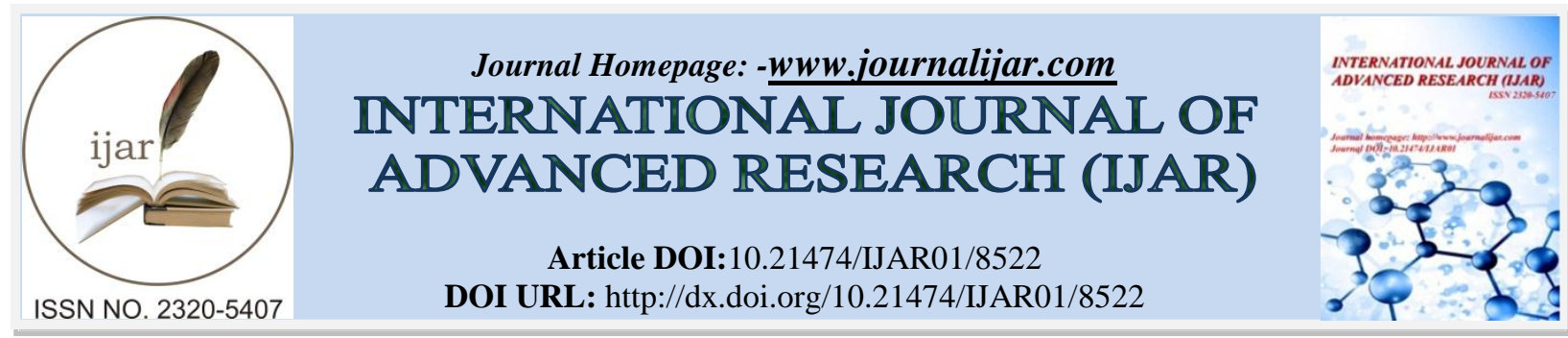

RESEARCH ARTICLE

\title{
SYNTHESIS OF POLYPROPYLENE HYBRID COMPOSITE BASED ON AGAVE AMERICANA, STARCH AND NANO-TALC USING TWIN SCREW EXTRUDER.
}

\author{
Bajwa G. S. ${ }^{1}$, Ranganath M. S. ${ }^{2}$, Mishra R. S. ${ }^{2}$ and Aftab Alam ${ }^{1}$. \\ 1. G.N.D. Institute of Technology, Rohini, Delhi-89 (India). \\ 2. Delhi Technological University, Bawana Road, Delhi-42 (India).
}

\section{Manuscript Info}

Manuscript History

Received: 06 December 2018

Final Accepted: 08 January 2019

Published: February 2019

Key words:-

Hybrid composite, Polypropylene, thermoplastic starch, Agave Americana, Nano Talc, FTIR, Melt Flow Index, SEM.

\begin{abstract}
In this research, hybrid composites of Agave Americana fibres, starch and nano-talc reinforced Polypropylene (PP) have been prepared by melt compounding reactive blending using maleic anhydride grafted polypropylene (PP-g-MA) as compatiblizer in co-rotating twin screw extruder. Sustainability, eco-friendly and green chemistry are guiding forces behind the development of this hybrid-composites. The biobased material obtained from renewable and agriculture waste can form the basis of new generation composite materials that can compete with currently dominated composites. The dispersion, thermal, and morphological properties of natural fibre in thermoplastic starch and polypropylene has been investigated. The chemical structure has been analyzed by FTIR and morphology of hybrid composites shows the uniform dispersion of natural fibre in the polypropylene matrix along with potato starch.
\end{abstract}

Copy Right, IJAR, 2019,. All rights reserved.

\section{Introduction:-}

Polypropylene is one of the important thermoplastic polymers as it is light weight, excellent mechanical properties, good heat and chemical resistance. It is easily processable, economical, and have good impact resistance. Due to these outstanding properties, polypropylene is becomes a fastest growing thermoplastic in commodity and engineering applications. Polypropylene is a non-biodegradable thermoplastic. Due to the increased environment concern a new class of biodegradable polymer emerages, which are produced from biomaterial [1]. The biodegradables opened the way for new opportunities of waste management as these materials are designed to degrade under environmental conditions. Natural fibres reinforced thermoplastics are also entering the global market of composite materials. Natural fibre composites consist of bio degradable or easily recyclable polymer and different natural fibres reinforcement [2-3]. The natural fibres such as flax, hemp, and kenaf, are renewable in nature, and can replace the traditional glass fibre reinforcement in polymeric composites. The lower density, high specific modulus and non-abrasive nature of natural fibres as compared to higher density, abrasive glass fibres helps in produceing light weight structures especially useful in automobile sector and construction sector. The future research on natural fibres reinforced PP composites is mainly focused on cost effective modification of natural fibres. The report related to the comparison of life cycle assessment of natural fibre composite with glass fibre reinforced composite, have found that natural fibre composites are superior in the specific automobile applications due to their low density and easily recyclability[4-6].

Corresponding Author:-Bajwa G. S.

Address:-G.N.D. Institute of Technology, Rohini, Delhi-89 (India). 
Talc, mica and kaolin are used to enhance the stiffness and strength of filled polymers. The properties of polymer composites are determined by component properties (matrix and filler). In addition to the matrix /filler properties, the mechanical characteristics of these materials are significantly influenced by inter facial interaction which depends on the size of the interface and strength of the interaction [7]. Fibrous filler can usually improve the tensile strength and plate like filler increases rigidity. Talc and kaolin are plate like fillers. Filler with high specific surface area will contribute to more surface contact between the fillers and matrix, herby increasing the mechanical properties of the composites.

In nanotechnology, polymer nanocomposites are defined as solids consisting of a mixture of two or more phase separated fillers, where one or more constituents phase is in nano scale in a polymeric matrix. Materials can be referred to as nano-scaled when their size, atleast one of the dimensions lie in the range of $1 \mathrm{~nm}$ to $100 \mathrm{~nm}$ [8]. There are number of nano-particle that has been used in nanocomposites. These particles are divided in fibres (1D), platelets (2D), and particles (3D) depending upon the number of dimensions they display in Nano scale. Performance of nanocomposite depends on various features of nanoparticle such as the size, specific surface area, aspect ratio, compatibility and dispersion of reinforcement in polymeric matrix. Nano material is extensively used in polymer to enhance their properties as shown by number of review articles. Nano dimensions particles effects the transition zone between the macro-level and molecular level resulted in large modification in the properties of polymer Nano composite materials [9-11]. Nano-material increases the surface area to a great extent and it offer sites for interaction between reinforcement and polymer matrix. Hence, this fraction of polymer contributes, significantly to the improvement of properties of the whole nanocomposite. In this respect, polymers nanocomposites are somehow similar to semi crystalline polymers where the crystals can be considered as nano fillers [12].

Hybrid composite reinforced with more than one filler is an easy way to achieve suitable improved mechanical properties [13-15]. The hybrid polymeric composites reinforced with natural fibre and nano material may contribute towards enhanced mechanical and thermal properties. Natural fibre composite are available at low cost and their friendly environment character, are the main reasons for an increase in interest in their development. Further the natural fibre hybrid composites are recyclable and biodegradable. A mechanical property of hybrid composites depend strongly on the filler morphology, filler content, dispersion of filler material into matrix and filler/matrix adhesion [16-19].

Talc qualifies as good reinforcement filler alternate to clay because it is layered mineral with a high aspect ratio (particle diameter/thickness 20:1) this is due to its plate type structure having micron sized dimensions on length and width with nanometric thickness. The effects of talc on polymer have been well studied. It was demonstrated that talc improves mechanical properties of polypropylene [20].

In this present work, authors selected Nano Talc, Natural fibre of Agave Americana, starch and Polypropylene to develop hybrid composites. This combination of materials may offer outstanding performance and properties of talc, and natural fibre has been quite a low cost and easily available material with multi-dimensional properties and applications and more importantly natural fibre of Agave Americana is cosmetic crops and agro-waste. The incorporation of starch as bio-material has been reduced the burden on fossile fuel. In this research work the content of compatibilizer was kept constant which is $10 \%$., while the content of agave Americana and nano talc is given in table no. 1. These samples have been reactive melt blended in co-rotating twin screw extruder. The hybrid composites so obtained were evaluated and the role of reinforcement of talc, strach and agave-amreicana fibres has to be discussed based on the morphology and properties relationship.

\section{Experimental \\ Materials:-}

Polypropylene (homo polymer) in powder form specifications (MFI $35 \mathrm{gm} / 10 \mathrm{~min}$ at $230^{\circ} \mathrm{C} / 2.16 \mathrm{Kg}$ load, Grade PP $\mathrm{H} 350 \mathrm{FG}$ ) was procured from M/S Reliance Industries. The potato starch having molecular weight 162.14 was procured from Loba Chemie, Mumbai. The maleic anhydride grafted PP (PP-g-MA) grade Epolene G-3015 was procured from Eastman Chemical Products Co., USA. The glycerol was obtained from M/s Fisher Scientific (99.5\% pure). Natural fibre extracted from Agave Americana plant by wetting process. 


\section{Extraction of Fiber:}

The extraction of fibres involves retting process followed by decorticating. The photograph of plant Agave Americana (Natural Fibres) at our university campus and chopped fiber are shown Figure 1. The leaf of the Agaveamericana plant was cut manually and immersed in a water retting tank for two weeks. Later, they are removed, and fibre were stripped from the leaf by hand, washed and dried in the sun. The extracted natural fibre was treated with $0.5 \% \mathrm{NaOH}$ solution at $80{ }^{\circ} \mathrm{C}$ for $30 \mathrm{~min}$ and then washed with running tap water until the $\mathrm{pH}$ value reached nearly 7. The alkali treated fibres were then oven dried and finally cut into an approximately $2 \mathrm{~mm}$ length size and oven dried in vacuum for overnight and packed into plastic zipper bag till melt blending.
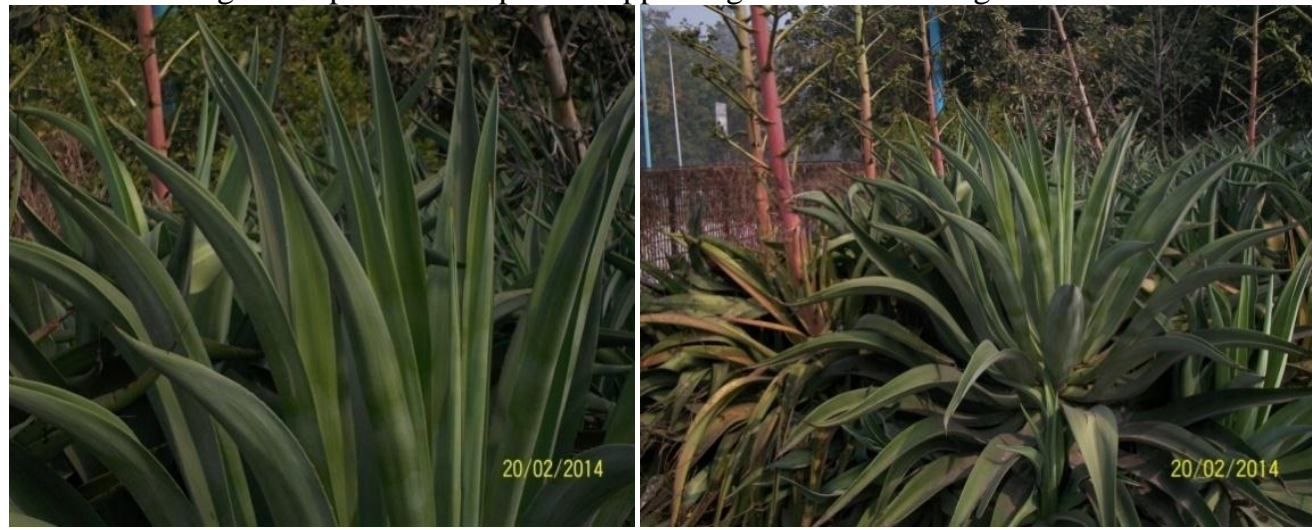

Figure no.1:-Plant of Agave Americana

\section{Preparation of Hybrid Blends:}

The Polypropylene, Nano talc, and starch in powder form and Agave Americana fibres were mixed homogeneously in the high speed mixer for 2 min as per formulation given in Table 1. and blends were prepared by melt blending via co-rotating twin screw extruder.

Table No.1:-Formulation of Hybrid composites

\begin{tabular}{|l|l|l|l|l|l|}
\hline S.No. & Sample & $\begin{array}{l}\text { Polypropylene } \\
(\mathrm{PP}) \%\end{array}$ & Starch (ST) \% & $\begin{array}{l}\text { Nano Talc } \\
(\mathrm{TL}) \%\end{array}$ & $\begin{array}{l}\text { Natural Fibre } \\
(\mathrm{NF}) \%\end{array}$ \\
\hline 1 & PP & 100 & 00 & 00 & 00 \\
\hline 2 & PPST20TL01NF05 & 100 & 20 & 01 & 05 \\
\hline 3 & PPST20TL03NF03 & 100 & 20 & 03 & 03 \\
\hline 4 & PPST20TL05NF01 & 100 & 20 & 05 & 01 \\
\hline 5 & PPST00TL05NF00 & 100 & 00 & 05 & 00 \\
\hline
\end{tabular}

The details of processing parameters used in processing of biocomposites are given in Table no. 2.

Table 2:-Processing parameters for processing of PP based hybrid composites.

\begin{tabular}{|c|c|c|c|c|c|c|c|c|c|c|c|}
\hline $\begin{array}{c}\text { Parameter/ } \\
\text { Polymer }\end{array}$ & $\begin{array}{c}\text { Z-1 } \\
{ }^{0} \mathrm{C}\end{array}$ & $\begin{array}{c}\text { Z-2 } \\
{ }^{0} \mathrm{C}\end{array}$ & $\begin{array}{c}\text { Z-3 } \\
{ }^{0} \mathrm{C}\end{array}$ & $\begin{array}{c}\text { Z-4 } \\
{ }^{0} \mathrm{C}\end{array}$ & $\begin{array}{c}\text { Z-5 } \\
{ }^{0} \mathrm{C}\end{array}$ & $\begin{array}{c}\text { Z-6 } \\
{ }^{0} \mathrm{C}\end{array}$ & $\begin{array}{c}\text { Z-7 } \\
{ }^{0} \mathrm{C}\end{array}$ & $\begin{array}{c}\text { Z-8 } \\
{ }^{0} \mathrm{C}\end{array}$ & $\begin{array}{c}\text { Melt } \\
\text { Temp } \\
{ }^{0} \mathrm{C}\end{array}$ & $\begin{array}{c}\text { Screw } \\
\mathrm{RPM}\end{array}$ & $\begin{array}{c}\text { Melt } \\
\text { Pressure } \\
\text { MPa }\end{array}$ \\
\hline $\begin{array}{c}\text { PP Hybrid } \\
\text { composite }\end{array}$ & 190 & 190 & 200 & 200 & 210 & 210 & 180 & 180 & 170 & 275 & 25 \\
\hline
\end{tabular}




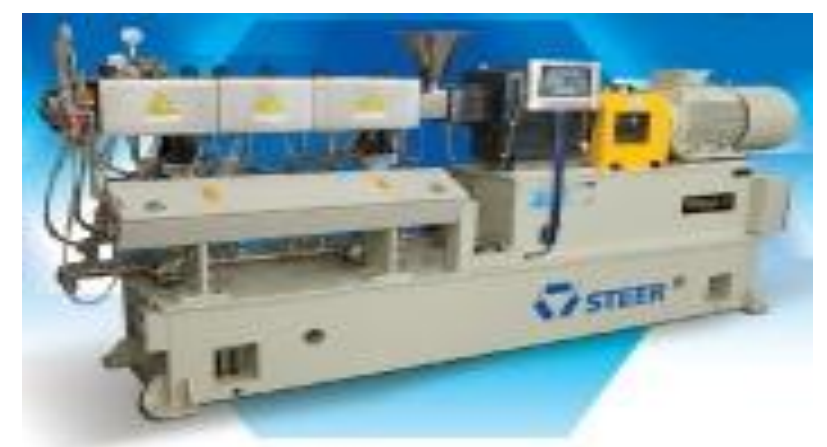

Figure 2:-The co-rotating Twin Screw Extruder used for melt reactive blending

\section{Characterization:}

Fourier Transmission Infrared Spectroscopy (FTIR):

The chemical structure analysed by FTIR. It shows the interaction between the PP chains and other filler materials. The samples have been scanned in frequency range 4000 to $550 \mathrm{~cm}^{-1}$. FTIR test conducted according to ASTM E 1252:2013 with ATR (Attenuated Total Reflection)

\section{Melt Flow Index:}

The Melt Flow Index for the blends has been conducted according to ASTM D 1238. The test conducted at $230^{\circ} \mathrm{C}$ at $2.16 \mathrm{~kg}$ load on Ceast Spa equipment. Five tests were done to obtain the average value of the melt

\section{Scanning Electron Microscopy (SEM)}

The scanning electron microscopy (SEM) of Hitachi-Japan Model no S-3700N was used to perform SEM analysis to observe microstructure of the samples. The morphological analysis was performed on fractured surfaces of test specimens. The samples were first dried in an oven to remove the moisture and then sputter coated with a thin layer of gold to avoid electrical charging. Imaging of the samples was carried out under high vacuum with operating at 15 $\mathrm{kV}$.

\section{Results And Discussion:-}

\section{Fourier Transmission Infrared Spectroscopy (FTIR):}

Figure 3 illustrates FTIR of hybrid composite of Polypropylene reinforced with potato starch, natural fibre, and talc. FTIR spectroscopy employed to prove the compatibilization among various constituents of hybrid composite. Several strong peaks were observed in $2850-2950 \mathrm{~cm}^{-1}$ which indicates asymmetric vibration of C-H bond, $1747 \mathrm{~cm}^{-1}$ $\left(\mathrm{C}=\mathrm{O}\right.$ stretching from starch and anhydride group), $1456 \mathrm{~cm}^{-1}$ and $1376 \mathrm{~cm}^{-1}$ (indicates $\mathrm{CH}_{3}$ group), peaks at $1167,1016,973 \mathrm{~cm}^{-1}$ confirmed the prescience of the PP component in all the samples. The peak observed near $1747 \mathrm{~cm}$ indicating that anhydride group is present as compatibilizer.609, 708 and $841 \mathrm{~cm}^{-1}$ confirms the presence of saccharides structure in sample no 2, 3, and 4 respectively, which is present in natural fibres agave Americana. 


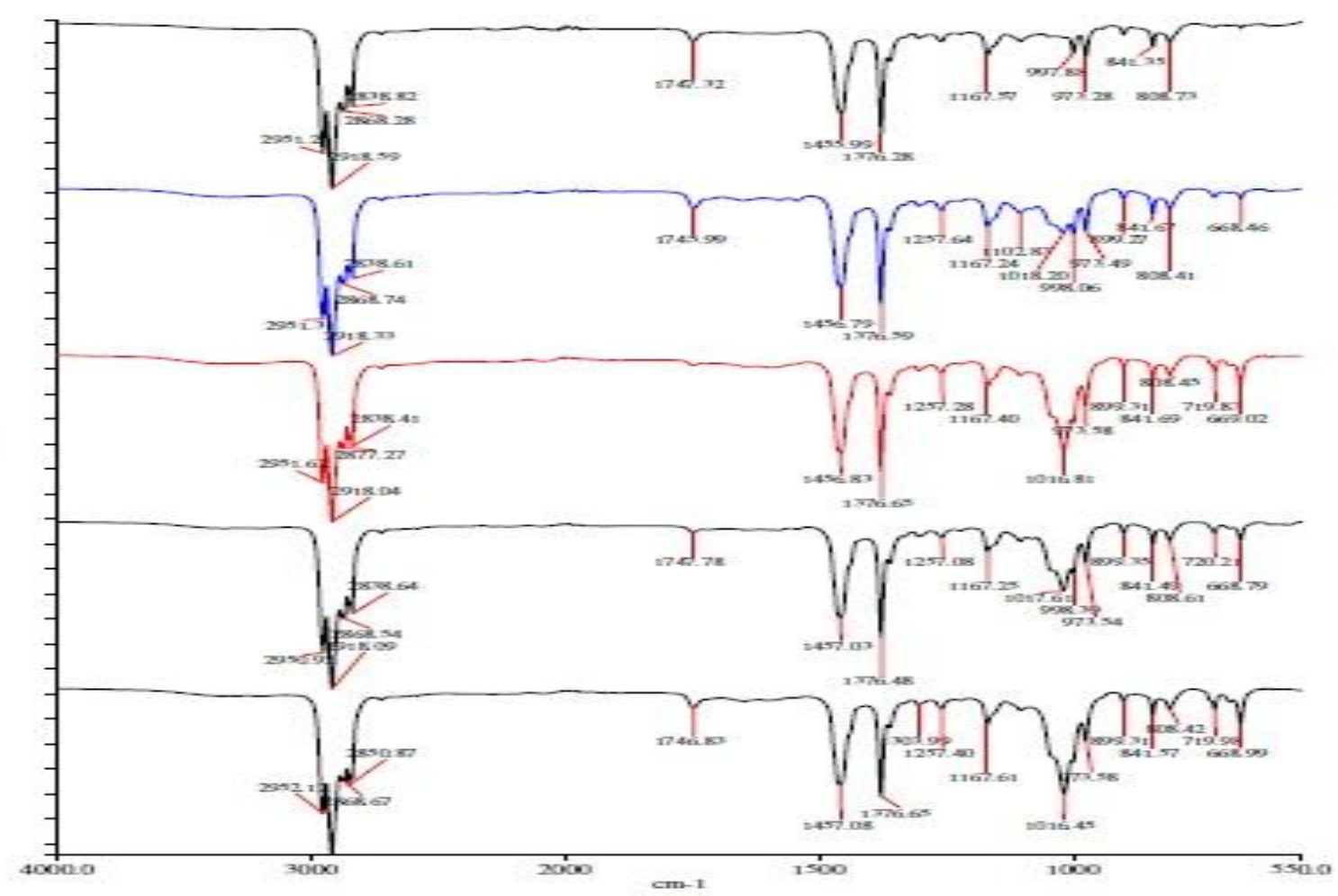

Figure 3:-FTIR spectra of Hybrid composites of all five samples.

\section{Melt Flow Index:}

The melt flow index (MFI) is used as a means of measuring of the flow rate of the thermoplastic polymers. It is the most accepted and widely used practical method to relate the molecular weight and viscosity of the polymer and widely used in industry. The MFI value of different compositions of biocomposites were shown in Table 3 . The MFI value of sample no. 5 was slightly increased by as compared with pure PP, which indicates the uniform distribution of nano talc in the polypropylene matrix. The addition of natural fibers to hybrid composities were decreased the melt flow as expected from the fact that addition of natural fiber hindered the flow of polymers becasue of surface roughness of natural fibers.

Table 3:-The Melt Flow Index of Hybrid composites

\begin{tabular}{|l|l|l|}
\hline s.no. & Sample & Melt Flow Index \\
\hline 01 & PP & 35.4 \\
\hline 02 & PPST20TL01NF05 & 26.4 \\
\hline 03 & PPST20TL03NF03 & 27.8 \\
\hline 04 & PPST20TL05NF01 & 32.7 \\
\hline 05 & PPST00TL05NF00 & 36.3 \\
\hline
\end{tabular}

\section{Morphological Analysis:-}

Figure shows scanning electron micrographs (SEM) of pure PP and Hybrid composites of natural fibre, nano talc and starch. These images show that the thermoplastic starch and natural fibres are being continuously and uniformly dispersed in polypropylene and form a finely dispersed homogeneous phase of the composite. The coupling agent PP-g-MA played a vital role in reducing the interfacial energy and promoting the interfacial adhesion between the potato starch, natural fibre, nano talc and polypropylene matrix. The PPST20TL01NF05 having maximum content of natural fibre, this image clearly shows that the natural fibre agave americana were well embedded in the polymer matrix, and this improved the compatibility and adhesion among the filler-matrix polymer of hybrid composites. 

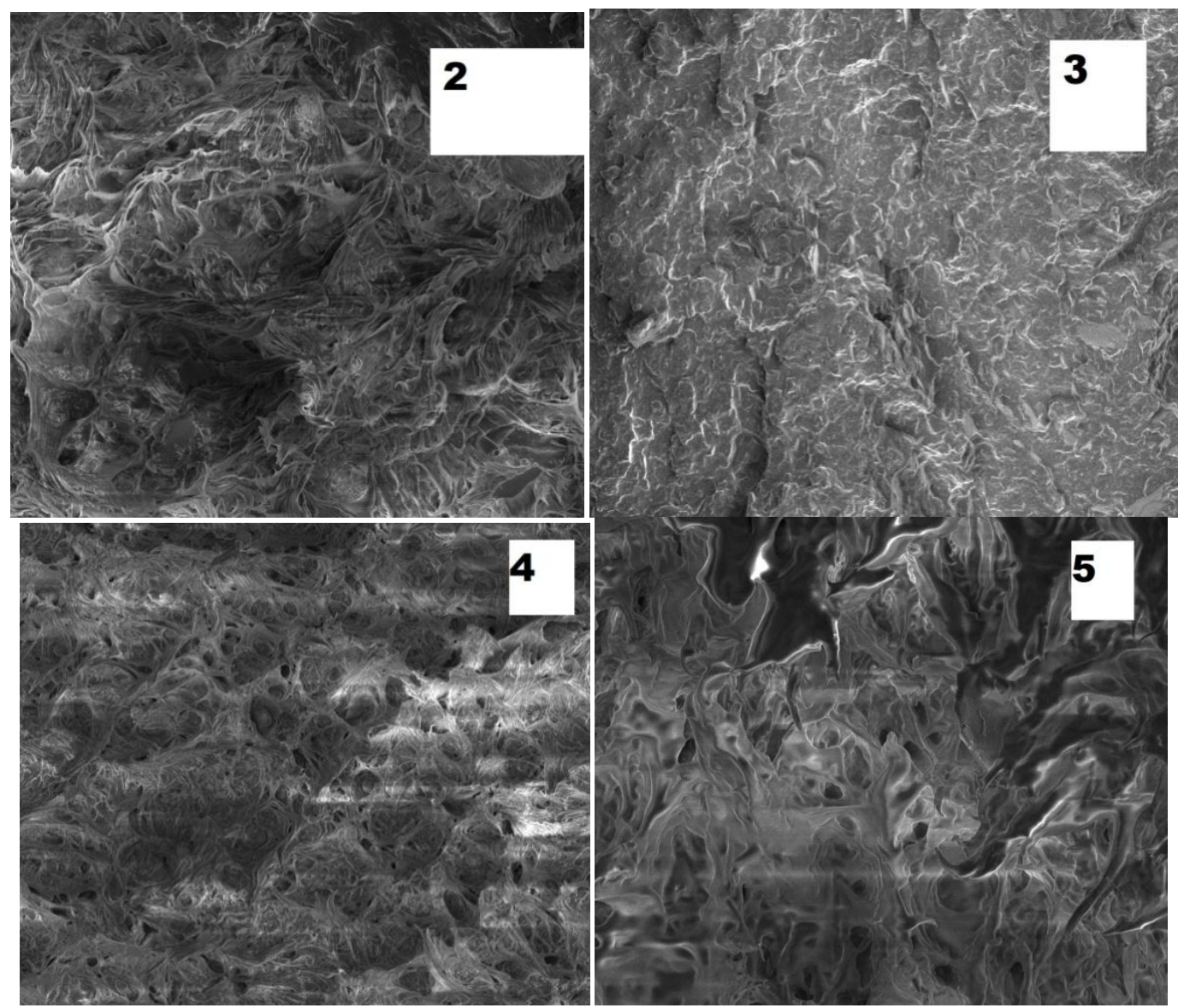

Figure 4:-SEM micrograph of Hybrid composites of sample 2 to 5 at 50 micron magnification.

\section{Conclusion:-}

The FTIR, morphological, and thermal properties of Nano talc/starch/ Agave Americana (Natural fiber) / Polypropylene Hybrid composites of melt blended were studied. The morphological characterization based on scanning electron microscopy (SEM) has confirmed that natural fibres, starch and nano talc were distributed uniformly indicating a good dispersion of natural fibers, nano talc and thermoplastic potato starch in the PP/PP-gMA matrix. The SEM images of Agave Americana natural fibers composite are quite stable, and the filler particles are well dispersed in the polymer matrix along with thermoplastic starch. This behaviour indicates a strong interaction between the filler matrix inter-phase due to the presence of maleic anhydride based compatibilizer (PP-gMA). Thus, the results indicated that PP-g-MA is an effective dispersing agent for biocomposites.

Finally, it conclude that the hybrid composite of starch, nano talc and Agave Americana natural fiber prepared from melt extrusion using PP-g-MA having better properties, reduce the burden on fossil fuels and green look. The injection moulding of hybrid composites specimen consumes almost $17 \%$ less energy as compared with virgin PP specimens moulding, and are fully recyclables at the end of life cycle, which gives better calorific values as fossil fuel. This development may prove a milestone towards developing bio-based polymeric hybrid composite in future in high-end application with multi-dimensional properties. 


\section{Reference:-}

1. Stevens E.S., "Green Plastics: An Introduction to the new science of biodegradable plastics" , Princeton University Press, Princeton, New Jersey,2002

2. Zini,E., Scandola M., "Green Composites: An overview", Polymer composites, 2011, 32(12), 1905-15.

3. Bogoeva-Gaceva G., Avella M., Malinconico M., Grozdanova A., Gentile G., Errico M.E., "Natural fibre ecocomposites", Polymer Composites,2007,28,98-107

4. $\mathrm{Ku} \mathrm{H.,} \mathrm{Wang} \mathrm{H.,} \mathrm{PattarachaiyaKoop} \mathrm{N.,} \mathrm{Trda} \mathrm{M.,"A} \mathrm{review} \mathrm{on} \mathrm{the} \mathrm{tensile} \mathrm{properties} \mathrm{of} \mathrm{natural} \mathrm{fibre} \mathrm{reinforced}$ polymer composites", Composite Part B-Engg., 2011, 42(4), 856-873

5. Shazad A.,"Hemp fibre and its composite-A review" J.Composite Material, 2012, 46(8), 973-986

6. SanzMirabal A., Scholz L., MCarus, "Market study on biobased polymers in the word-capacities, production and application: status quo and trends towards 2020", Nova-Institute,GmbH,2013

7. Demjen Z. , Pukanszky B., Nagy "J. Compos A,1998,29,323

8. Intrernational Organization for Standarization (ISO), Nanotechnologies-Vocabulary, part4; Nanostructural Materials, International Organization for Standardization, Geneva, Switzerland, 2011

9. Paul D. R., Robeson L. M.,'Polymer nanotechnology: Nanocomposites”, Polymer 2008,49,3187-3204

10. Alexandre M., Dubois P.,'Polymer-layered silicate nanocomposites: preparation, properties and uses of a new class of materials", Mater. Sci.Engg., 2000,28, 1-63

11. Ferreira J. A. M., Reir P. N. B., Costa J. D. M., Richardson B. G. H., Richardson M. O. W., ”A study on mechanical properties on poly propylene enhanced by surface treated nanoclays" Composite Part B:Eng.2011,42,1366-1372

12. Kawasumi M., Hasegawa M,N, Kato M., Usuki A., Okada A., "Preparation and mechanical properties of polypropylene-clay hybrids", Macro molecules,1997,30,6333-6338

13. Verma D., Gope P.C., "The use of coir /coconut fibers as reinforcements in composite" Composite matrrials, 2015,285

14. Jawaid M., Abdul Khalil H.P.S., Abu Bakar M., "Chemical resistance, void contents and tensile properties of oil palm/jute fiber reinforced polymer hybrid composite" Mater. Des.2011,32,1014

15. Kakou C.A, Esaabir H., BensalahM.O., Bouhfid R., Rodrigue D., Qaiss A, "Hybrid composite based on polyethylene and coir/oil palm fibers", J. Reinf. Plast. Compos. 2015, 34(20), 1684

16. Taj S., Munawar M.A., Khan S., "Natural fiber-reinfoced polymer composite” Proc. Pakistan Acad. Sci, 2007, 44(2), 129-144

17. Gupta M.K., Srivastava R.K., "Mechanical Properties of Hybrid Fibres-Reinforced Polymer Composites: A Review", Polymer Plastic Technology Engg., 2016, 55, 626-42

18. Yan Z.L., Wang H., Lau K.T., Pather S., Zhang J.C., Lin G., "Reinforcement of polypropylene with hemp fibres", Composite Part B, 2013, 46, 221-26

19. Del Rey R., Serrat R., Alba J., Perez I., Mutje P., Espinach F.X., "Effect of sodium hydroxide treatment on the tensile strength and the interphase quality of hemp core fibre reinforced polypropylene composite", Polymer 2017, 9, 377

20. Castillo L., Lopez O., Lopez C., Zaritzky N., Gracia M. A., Barbosa S., Villar M., "Thermoplastic starch films reinforced with talc nanoparticles", Carbohydrate Polymer,2013, 95, 664-674. 